\title{
Thermal characterization of polymeric anion exchangers with a dendrimeric structure
}

\author{
Marta Grochowicz • Barbara Gawdzik • \\ Magdalena Jaćkowska $\cdot$ Bogusław Buszewski
}

Received: 26 November 2012/ Accepted: 20 February 2013/Published online: 20 March 2013

(C) The Author(s) 2013. This article is published with open access at Springerlink.com

\begin{abstract}
The thermal properties of new anion exchangers prepared via the grafting process to polymeric particles having hydroxyl groups on their surface were evaluated by thermogravimetry and differential scanning calorimetry. The support microspheres were copolymers of 1,4-di (2-hydroxy-3-methacryloyloxypropoxy)benzene (1,4 DMH) and trimethylolpropane trimethacrylate (TRIM). They were coated with polymeric layers formed by condensation polymerization of primary amines with diepoxides. Synthesized copolymers of methylamine and 1,4-butanedioldiglycidyl ether have a dendrimer structure. By TG/FTIR/ MS, it was observed that new dendrimeric materials exhibited one stage of mass loss with $T_{\max 1} 400^{\circ} \mathrm{C}$, connected with degradation of organic layers. DSC and TG experiments showed that water molecules are absorbed on the materials surface. The synthesized anion exchangers exhibited good thermal stability, suitable for their use in chromatographic experiments carried out with higher temperatures.
\end{abstract}

Keywords Polymeric anion exchangers . Thermal stability · Thermogravimetric analysis . TG/FTIR/MS

M. Grochowicz $(\bowtie) \cdot$ B. Gawdzik

Department of Polymer Chemistry, Faculty of Chemistry, Maria Curie Sklodowska University, Gliniana 33, 20-614 Lublin, Poland

e-mail: mgrochowicz@umcs.pl

M. Jaćkowska · B. Buszewski

Chair of Environmental Chemistry and Bioanalytics, Faculty of Chemistry, Nicolaus Copernicus University, Gagarina 7, 87-100 Toruń, Poland

\section{Introduction}

Crosslinked polymeric microspheres with developed porous structure have many applications including the stationary phases for chromatography [1-3] and supports for exchange of ionic compounds [4-6]. The chemical structure of polymeric stationary phases determines their use in the separation of different types of organic compounds. Functional microspheres can be prepared by polymerization of functional monomers [7-9] or chemical modification of primary particles $[10,11]$. The process of grafting to polymer surface is one way of the permanent functionalization of polymeric particles. Covalent attachment of organic parts onto a polymer surface assures the long-term chemical stability of introduced chains, in contrast to physically coated polymer chains [12-14]. Most stationary phases currently used for separation of ionic compounds are based on organic polymers as well as silica gel. In contrast to stationary phases prepared on silica gel, organic polymers show higher stability in extreme $\mathrm{pH}$ conditions. The silica-based anion exchangers can be operated only in between $\mathrm{pH}$ 2.0-9.5 while polymeric ion exchangers are stable across the entire $\mathrm{pH}$ range. One of the most popular anion exchange groups in the structure of the stationary phases used in ion chromatography (IC) are the quaternary ammonium groups $[15,16]$. This type of stationary phases exhibits good selectivity for the separation of inorganic and organic anions. Quaternary ammonium groups can be incorporated in the structure of anion exchangers as a result of condensation polymerization of primary amine with diepoxide [methylamine (MA) and 1,4-butanedioldiglycidyl ether (BDDE)] [16-20]. In this type of synthesis, the tertiary amine and quaternary ammonium groups are formed, which are anion exchange centers when they are used in IC. In our previous papers, we have reported on 
the synthesis, application, and thermal properties of the new type of anion exchangers based on silica [21]. Our new conception was to obtain anion exchangers based on 1,4 DMH-TRIM polymeric microspheres [22]. Their synthesis and the utilization in ion chromatography was reported earlier [19, 23]. This paper is a report on the thermal properties of prepared polymer-supported organic materials with dendrimer structure using differential scanning calorimetry (DSC) and thermogravimetry coupled with FTIR and MS to analyze the evolved products during their decomposition.

\section{Experimental}

Materials

Laboratory-prepared 1,4 DMH-TRIM microspheres with particle diameter of 5-10 $\mu \mathrm{m}$ were used as a support for the grafting process. Their synthesis and properties were presented earlier [21]. The following reagents were used for the chemical modification of the polymer support material: methylamine (MA, $40 \%$ in $\mathrm{H}_{2} \mathrm{O}, v / v$ ) and 1,4-butanediol diglycidyl ether (BDDE, $95 \%$ in $\mathrm{H}_{2} \mathrm{O}, v / v$ ). Both reagents were obtained from Sigma-Aldrich Chemie (Steinheim, Germany).

Preparation of anion exchangers

Figure 1 shows the chemical structure of the anion exchanger. This material was prepared by a modification of $5-10 \mu \mathrm{m}$ sized copolymeric microspheres of 1,4 DMHTRIM possessing hydroxyl groups on their surface. The polymer support was coated with polymeric layers formed by condensation polymerization of primary amine with diepoxide. The process was repeated to obtain the expected number of bonded layers. The synthesis of each step was carried out for $30 \mathrm{~min}$ in the temperature $333 \mathrm{~K}$. Synthesized grafted copolymers exhibit dendrimer structure. Detailed synthesis procedure of the anion exchanger was presented in our previous work [19]. The process was repeated three, seven, eleven, and fifteen times to make $3,7,11$, and 15-layers on the solid support, respectively.

\section{Methods of analysis}

Elemental analysis (CHN) was made using a Perkin-Elmer CHN 2450 analyzer (Palo Alto, CA, USA). ATR-FTIR spectra were recorded on a Tensor 27 (Bruker) spectrometer equipped with a diamond crystal. The spectra were recorded in the spectral range of $600-4,000 \mathrm{~cm}^{-1}$ with a resolution of $4 \mathrm{~cm}^{-1}$ and 50 scans.

Thermogravimetric analysis of materials was carried out with a Netzsch STA 449 F1 Jupiter thermal analyzer a

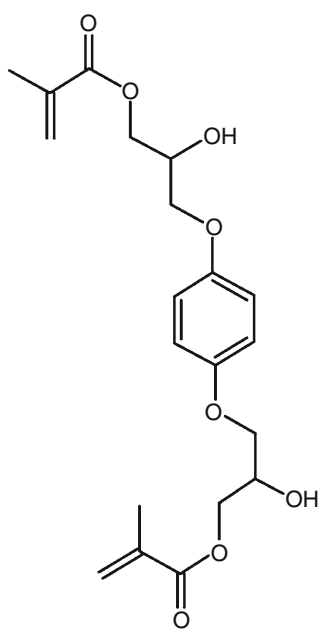

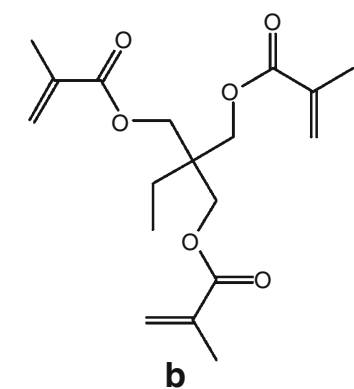

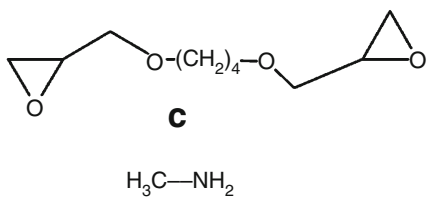

d
Fig. 1 Structure of chemicals used in the synthesis of dendrimeric materials: a 1,4-di(2-hydroxy-3-methacryloyloxypropoxy)benzene, 1,4 DMH; b trimethylolpropane trimethacrylate, TRIM; c 1,4-butanedioldiglycidyl, BDDE; d methylamine, MA

(Germany) at the heating rate of $10 \mathrm{~K} \mathrm{~min}^{-1}$, in the temperature range of $20-850{ }^{\circ} \mathrm{C}$, with the sample mass of $10 \mathrm{mg}$ in two atmospheres: argon and synthetic air $(80 \%$ nitrogen, $20 \%$ oxygen). The gas flow was $20 \mathrm{~mL} \mathrm{~min}^{-1}$. The gas composition evolved during the decomposition process was detected and analyzed by a quadrupole mass spectrometer QMS 403C Aëolos (Germany) as well as an FTIR Tensor 27 Bruker (Germany) spectrometer coupled on-line to a STA instrument. The mass spectrometer was connected on-line to the STA instrument by a quartz capillary heated to $300{ }^{\circ} \mathrm{C}$. The QMS was operated with an electron impact ionizer with the energy of $70 \mathrm{eV}$. The measurements performed in scan mode for $m / z$, where $m$ is the mass of the molecule and $z$ is the charge of the molecule in electron charge units in the range of 10 to $100 \mathrm{amu}$.

Calorimetric measurements were carried out with the Netzsch DSC 204 calorimeter (Germany) operating in the dynamic mode. The dynamic scans were performed at the heating rate of $10 \mathrm{~K} \mathrm{~min}^{-1}$ from room temperature to the maximum of $550{ }^{\circ} \mathrm{C}$ under $\operatorname{argon}\left(30 \mathrm{~mL} \mathrm{~min}^{-1}\right)$ and synthetic air $\left(30 \mathrm{~mL} \mathrm{~min}^{-1}\right)$ atmospheres in two stages. The first scan was performed from room temperature to the maximum of $120^{\circ} \mathrm{C}$ to remove any adsorbed moisture, especially water. The second scan was conducted between 20 and $550{ }^{\circ} \mathrm{C}$. The mass of the sample was $10 \mathrm{mg}$. As a reference an empty aluminum crucible was used.

\section{Results and discussion}

Condensation polymerization of primary amine MA and diepoxide BDDE carried out on the surface of polymeric 
Fig. 2 Structure of new anion exchanger

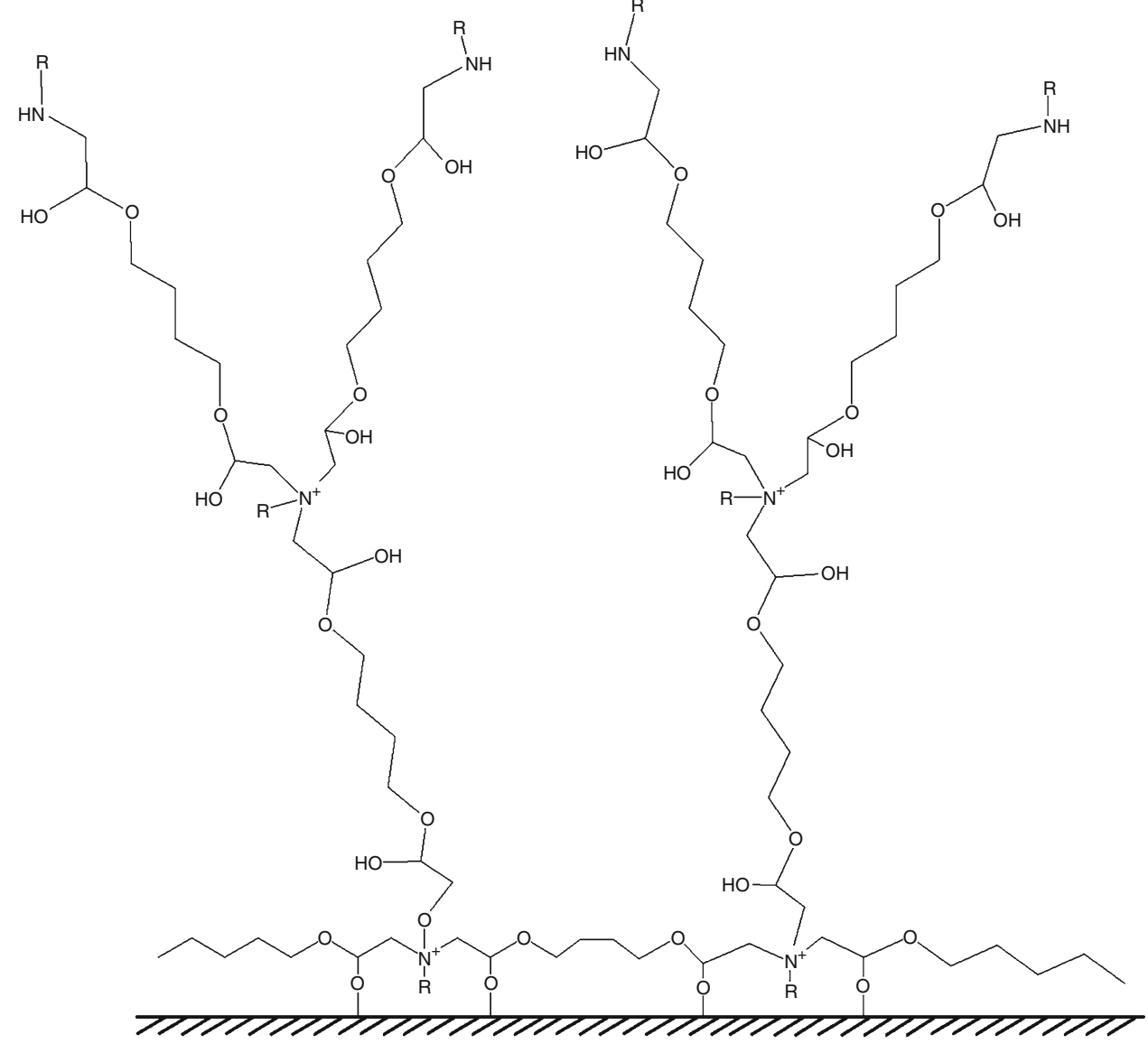

Table 1 Elemental composition of prepared anion exchangers

\begin{tabular}{llll}
\hline Material & $\begin{array}{l}\text { Nitrogen } \\
\text { content/\% }\end{array}$ & $\begin{array}{l}\text { Carbon } \\
\text { content/\% }\end{array}$ & $\begin{array}{l}\text { Hydrogen } \\
\text { content/\% }\end{array}$ \\
\hline Polymer & - & 59.92 & 7.40 \\
Polymer-3 layers & 0.65 & 58.57 & 7.84 \\
Polymer-7 layers & 1.09 & 56.91 & 8.23 \\
Polymer-11 layers & 1.29 & 56.41 & 8.67 \\
Polymer-15 layers & 1.44 & 56.35 & 8.82 \\
\hline
\end{tabular}

support 1,4 DMH-TRIM (Fig. 1) gives a series of new anion exchanger with dendrimer structure. After repeating the process, 3, 7, 11, and 15-layered materials were obtained. Their chemical structure and thermal behavior were evaluated by means of CHN analysis, FTIR spectroscopy, thermogravimetry, and differential scanning calorimetry.

In Fig. 2, a fragment of the structure of an anion exchanger is presented, whereas Table 1 shows the results of elemental analysis. It can be seen that the bare polymer does not contain any nitrogen. In polymer-layered materials, the percentage of nitrogen increases with the number of bonded layers from 0.6 to $1.44 \%$. It was expected that this growth should be exponential, but due to the steric hindrance exponential growth is not observed [19]. This suggests that the expected dendrimer structure is not obtained

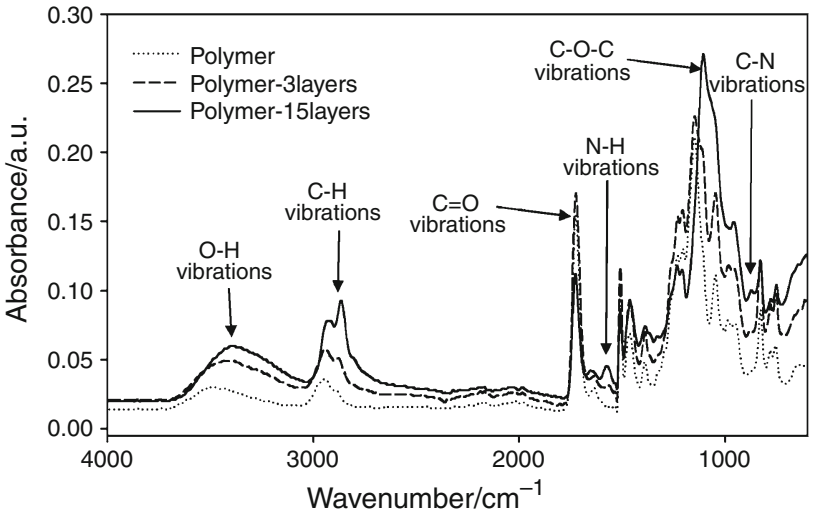

Fig. 3 FTIR spectra of prepared materials

for all the bonded layers. Figure 3 presents exemplary ATR-FTIR spectra of layered materials. The spectrum of the bare polymer bands at 1,450 and $2,930 \mathrm{~cm}^{-1}$ attributed to the $\mathrm{C}-\mathrm{H}$ vibrations in the $-\mathrm{CH}_{3}$ and $-\mathrm{CH}_{2}$ groups are observed. Absorption peak of the carbonyl group is present at $1,725 \mathrm{~cm}^{-1}$, and the band at $3,480 \mathrm{~cm}^{-1}$ is attributed to the $-\mathrm{OH}$ group vibrations. $\mathrm{C}-\mathrm{O}-\mathrm{C}$ group vibration is observed on the spectrum in the form of a strong width band with a maximum at $1,146 \mathrm{~cm}^{-1}$. The spectra of the covered materials are different from the spectrum of 1,4 


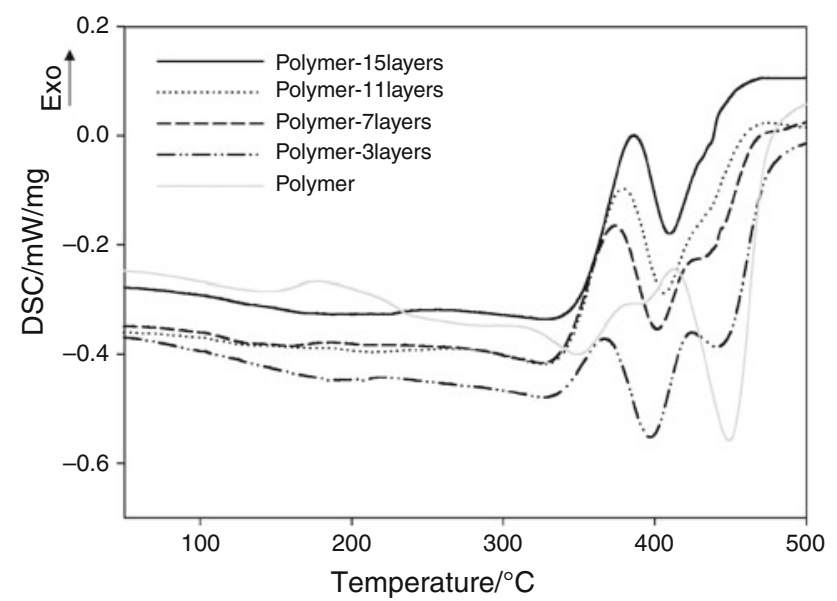

Fig. 4 DSC curves of silica composite materials covered by different number of organic layers obtained in argon atmosphere

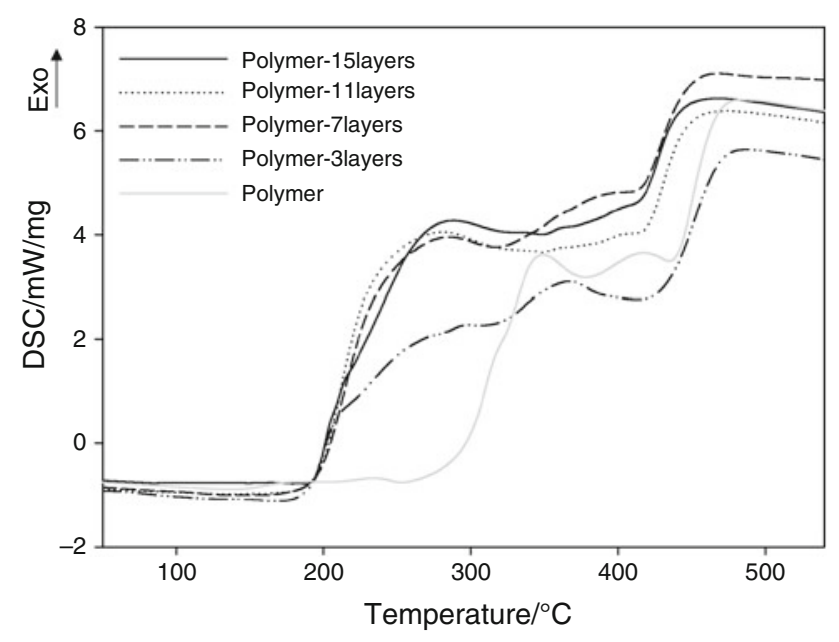

Fig. 5 DSC curves of silica composite materials covered by different number of organic layers obtained in air atmosphere

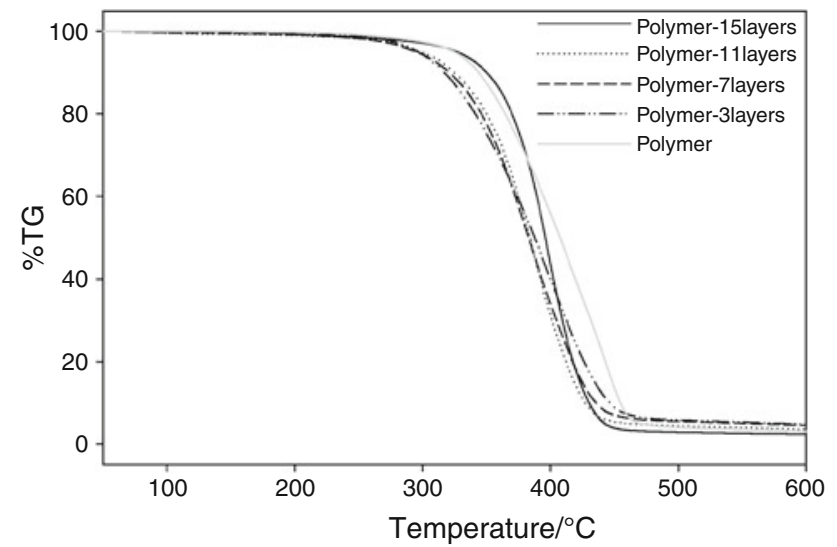

Fig. 6 TG curves of polymer-layered materials obtained in helium atmosphere

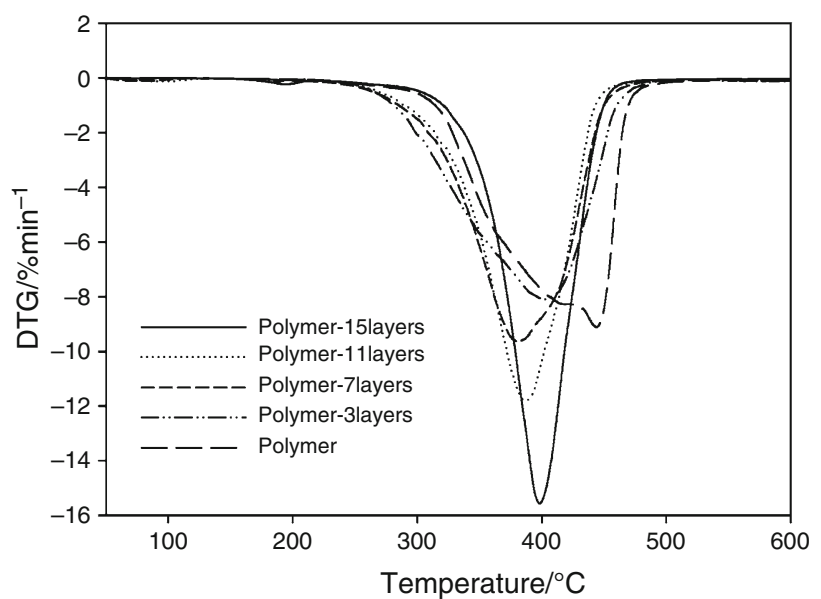

Fig. 7 DTG curves of polymer-layered materials

Table 2 Parameters evaluated from TG and DTG curves of anion exchangers

\begin{tabular}{llllc}
\hline Material & IDT $/{ }^{\circ} \mathrm{C}$ & $T_{50 \%} /{ }^{\circ} \mathrm{C}$ & $T_{\max 1} /{ }^{\circ} \mathrm{C}$ & $T_{\max 2} /{ }^{\circ} \mathrm{C}$ \\
\hline Polymer & 325 & 407 & 428 & 443 \\
Polymer-3 layers & 297 & 389 & 402 & - \\
Polymer-7 layers & 296 & 383 & 381 & - \\
Polymer-11 layers & 299 & 384 & 387 & - \\
Polymer-15 layers & 327 & 396 & 397 & - \\
\hline
\end{tabular}

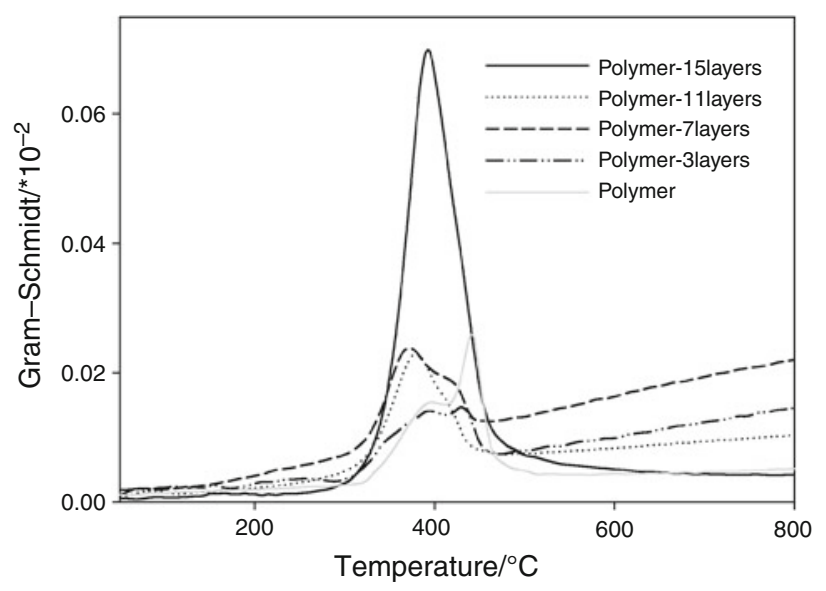

Fig. 8 Gram-Schmidt plots for investigated materials

DMH-TRIM copolymer. New absorption peaks present at 1,571 and $870 \mathrm{~cm}^{-1}$ correspond to the $\mathrm{N}-\mathrm{H}$ vibrations of the amine groups. Moreover, the presence of the $-\mathrm{CH}_{2}-$ groups adjacent to the $\mathrm{N}-\mathrm{H}$ groups in the structure of the layered materials shifted the peaks of $-\mathrm{CH}_{2}-$ vibrations to $2,864 \mathrm{~cm}^{-1}$ and the peak attributed to $\mathrm{C}-\mathrm{O}-\mathrm{C}$ vibrations from 1,146 to $1,104 \mathrm{~cm}^{-1}$. In addition, the overlapping of the $\mathrm{C}-\mathrm{N}$ vibration band on the $\mathrm{C}-\mathrm{O}-\mathrm{C}$ peak causes its broadening. Since in the layered materials, the $\mathrm{N}-\mathrm{H}$ groups and the $-\mathrm{OH}$ groups are present, the vibration of $-\mathrm{OH}$ is 


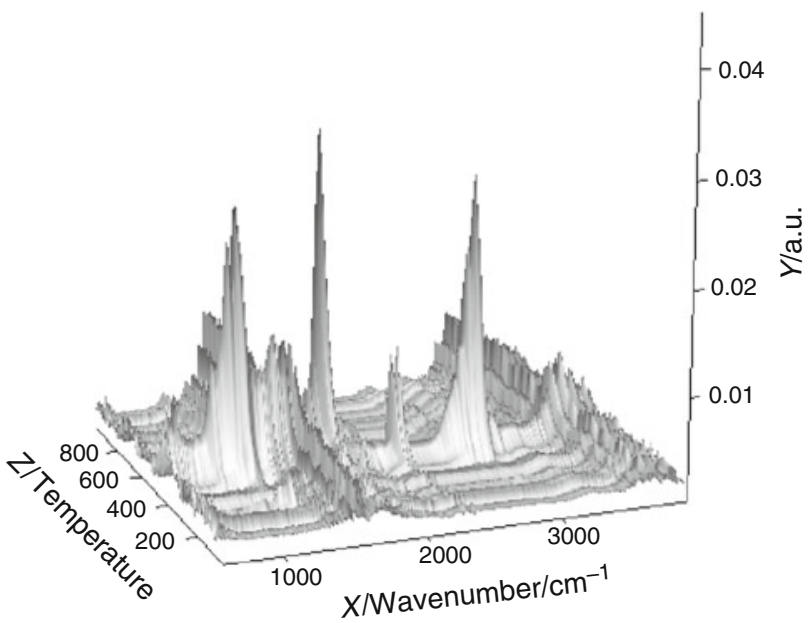

Fig. 9 Stacked plot diagram of evolved gases for polymer-15layers material

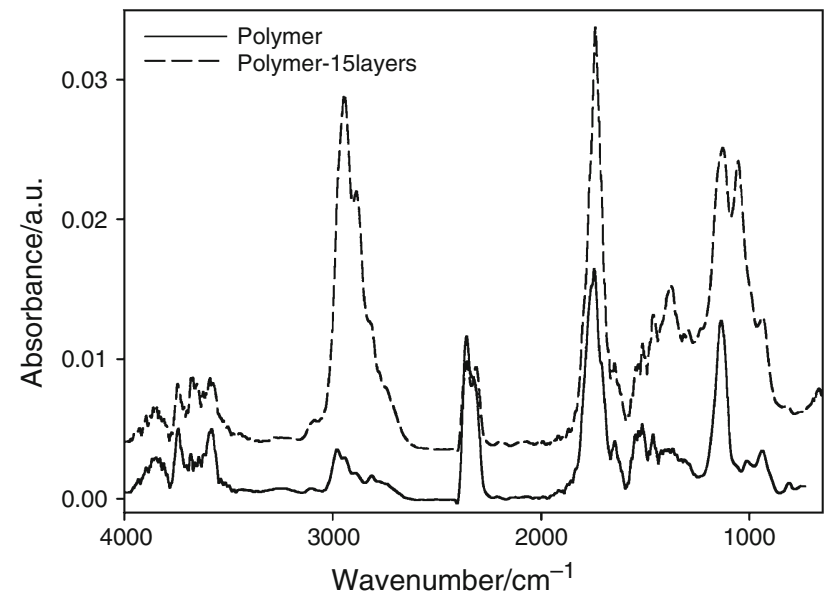

Fig. 10 TG/FTIR of gases evolved from polymer and polymer15layers material heated at $390{ }^{\circ} \mathrm{C}$

broadened. Furthermore, there is a possibility to create H-bonds in the network, which results in shifting broad band from 3,480 to $3,380 \mathrm{~cm}^{-1}$.

The DSC was performed in argon and air atmospheres in two steps: 20 to $120{ }^{\circ} \mathrm{C}$ and 20 to $550{ }^{\circ} \mathrm{C}$. In the first step, in both atmospheres, desorption of water from all materials was observed $[24,25]$. The second heating DSC curves of all the polymer-layered materials in argon are presented in Fig. 4. For the bare copolymer on the DSC curve, exo- and endothermic effects are observed. The exothermic peak with the onset at $150{ }^{\circ} \mathrm{C}$ corresponds to post-crosslinking of the copolymer [22]. This peak is followed by two endothermic ones. The first one with the onset at $315{ }^{\circ} \mathrm{C}$ is connected with the initial decomposition of ester and ether bonds in the material. The second one with the onset at $415^{\circ} \mathrm{C}$ is connected with the final decomposition of material. The DSC curves for layered materials exhibit another character. Along with the increased number of layers, new exothermic peaks are observed on DSC curves. For the 3-layer polymer, the exothermic peak with the onset at $326{ }^{\circ} \mathrm{C}$ appears, and is followed by the next endothermic peak with the onset at $420{ }^{\circ} \mathrm{C}$. This endothermic effect is connected with the decomposition of polymer core present in the material, whereas the exothermic peak is a result of the decomposition of grafted layers. The oxygen present in their structure causes autocatalytic exothermic oxidation of the organic layers. The same effect was observed for dendrimeric anion exchangers with silica core possessing analogical organic layers. For the materials studied, with an increasing number of layers the endothermic peak on the DSC curve becomes smaller, and for the 11-layer and 15-layer polymers it disappeared and the degradation process ran through only one step. Figure 5 presents DSC curves of all the polymer-layered materials conducted in air. In oxidative atmosphere, bare copolymer exhibits better thermal stability than covered materials. It starts decompose at $255{ }^{\circ} \mathrm{C}$ whereas covered copolymers decompose at about $180^{\circ} \mathrm{C}$. At first, the oxidative exothermic decomposition of organic layers is observed, and then the copolymeric core decomposed.

The change in the degradation character of the grafted materials is also observed in thermogravimetric results. The TG mass loss curves and the corresponding derivate curves are shown in Figs. 6 and 7, respectively. In addition, the characteristic data obtained from the TG analysis are given in Table 2. From the data presented, it is clearly visible that the 1,4 DMH-TRIM copolymer has a higher thermal stability than the grafted materials. Its initial decomposition temperature, IDT, determined at $5 \%$ of mass loss, and $T_{50} \%$ are higher than for the covered materials. The exception is the 15-layer polymer material, which exhibits a slightly higher value of IDT than the bare polymer and much higher ones than materials with other numbers of layers. It was unexpected, but $\mathrm{CHN}$ results indicate that the percentage of nitrogen in this material should be higher and suggest that external layers do not have dendrimer structure. Due to the high density of the grafted chains, intramolecular crosslinking with 1,4butanedioldiglycidyl ether of the last layers was possible $[26,27]$. This crosslinking probably shifted the start of the decomposition process to a higher temperature but after the initial step, degradation ran very quickly, just as in the case of other grafted materials. The DTG curves presented in Fig. 7 show that the thermal degradation of the polymer runs through two steps with $T_{\max 1}$ at $428{ }^{\circ} \mathrm{C}$ and $T_{\max 2}$ $443{ }^{\circ} \mathrm{C}$. The DTG profiles of polymers with grafted layers are changing: for the 3-layer polymer is close to bare polymer whereas for the 11-layer and 15-layer polymers only one step degradation is observed. It takes place at about $390{ }^{\circ} \mathrm{C}$. The IDT and $T_{\max }$ values for anion exchangers prepared on polymer core and silica support, presented in our previous paper, are comparable and close to 290 and $390{ }^{\circ} \mathrm{C}$. 
Fig. 11 MS profile of evolved gases from polymer-15layers material

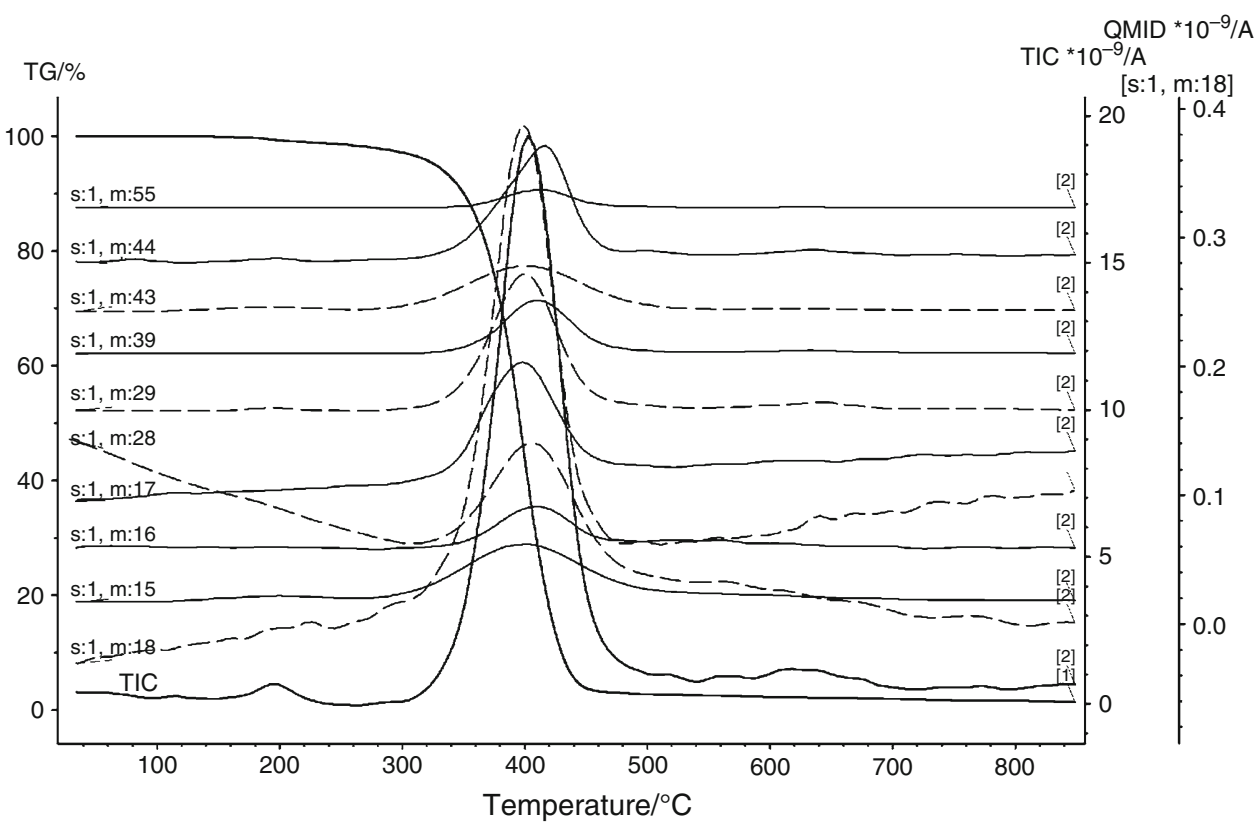

Moreover, thermodesorption of water from the surface of dendrimeric materials is also observed on TG curves at $100-140{ }^{\circ} \mathrm{C}$. The presence of absorbed water was confirmed by the IR and MS analyses of the evolved gases. Figure 8 shows the Gram-Schmidt plots that provide information about the total IR absorbance of the evolved components over the entire spectral range [28]. As can be seen, the Gram-Schmidt plots are convergent with the DTG plots and show a different character of the decomposition process of polymer and dendrimeric materials. The FTIR 3D spectrum of the evolved gases for the 15-layer polymers material is presented in Fig. 9, whereas the comparison of the FTIR spectra of the gases evolved at the maximum rate of the decomposition (at about $390{ }^{\circ} \mathrm{C}$ ) for polymer and 15-layer polymer materials is given in Fig. 10. The FTIR spectra exhibited bands related to aliphatic compounds $\left(2,978-2,820 \mathrm{~cm}^{-1}\right)$ as well as $\mathrm{CO}_{2}$ $\left(2,357\right.$ and $\left.2,311 \mathrm{~cm}^{-1}\right)$ and $\mathrm{CO}\left(2,182\right.$ and $\left.2,110 \mathrm{~cm}^{-1}\right)$. In the carbonyl region, bands at ca. $1,744 \mathrm{~cm}^{-1}$ attributed to the ester groups are observed. Moreover $\mathrm{C}-\mathrm{O}-\mathrm{C}$ vibration at $1,137 \mathrm{~cm}^{-1}$ is present on spectra. Finally, the presence of water (bands in the region of 3,700$3,600 \mathrm{~cm}^{-1}$ ) and methane (signal at $3,089 \mathrm{~cm}^{-1}$ ) during the thermal degradation of materials was observed. In addition, in the spectrum of the 15-layer polymer bands at 1,055 and $1293 \mathrm{~cm}^{-1}$ attributed to $\mathrm{N}-\mathrm{C}$ vibration derived from the decomposition of grafted layers. The MS profiles of the evolved gases confirm the results from the FTIR analysis. Exemplary MS results with the total ion current profile (TIC) and extracted ions for the 15-layer polymer are presented in Fig. 11. Evolution of water and ammonia $(m / z=18,17,16,15)$, carbon dioxide $(m / z=44)$, amine fragments $(m / z=28,29)$, carbon oxide $(m / z=28)$, aliphatic fragments $(m / z=15,42,43,56)$, and carbonyl fragments $(m / z=41,43)$ was detected. In the final decomposition, the material evolution of carbon dioxide was detected. Thermodesorption of water precedes the decomposition of material and take place at about $180{ }^{\circ} \mathrm{C}$ $(m / z=18)$.

\section{Conclusions}

The current work presents the thermal properties of a series of new anion exchangers obtained via grafting of organic chains to the surface of polymeric microspheres. The synthesized materials are thermal stable to about $295{ }^{\circ} \mathrm{C}$, depending on the number of grafted layers, whereas polymeric support is more stable; its IDT is $325^{\circ} \mathrm{C}$. Unexpectedly, the thermal stability of the 15-layer polymer material is higher than that of other layered materials and or of bare polymer. The CHN and TG analyses conducted suggest that the outer layers in this material are crosslinked with 1,4-butanedioldiglycidyl ether. In addition, previous experiments with the use of these materials as column packings in ion chromatography show that the 7-layered stationary phase gives optimal conditions for the separation. DSC and TG measurements indicated that organic layers grafted to the surface of methacrylate polymeric support altered its thermal degradation behavior. Layered materials exhibit only one maximum on DTG curves $\left(T_{\max 1} \sim 400{ }^{\circ} \mathrm{C}\right)$. The thermal stability of the prepared anion exchangers is sufficient to use them in chromatographic experiments carried out in higher temperatures. 
Acknowledgments The authors would like to thank Dr Szymon Bocian for his help in the preparation of new anion exchangers. The research was carried out with the equipment purchased, thanks to the financial support of the Operational Programme Development of Eastern Poland 2007-2013.

Open Access This article is distributed under the terms of the Creative Commons Attribution License which permits any use, distribution, and reproduction in any medium, provided the original author(s) and the source are credited.

\section{References}

1. Valero-Navarro A, Gomez-Romero M, Fernandez-Sanchez JF, Cormack PA, Segura-Carretero A, Fernandez-Gutierrez A. Synthesis of caffeic acid molecularly imprinted polymer microspheres and high-performance liquid chromatography evaluation of their sorption properties. J Chromatogr A. 2011;1218:7289-96.

2. Perrier-Cornet R, Heroguez V, Thienpont A, Babot O, Toupance T. Functional crosslinked polymer particles synthesized by precipitation polymerization for liquid chromatography. J Chromatogr A. 2008;1179:2-8.

3. Gawdzik B, Osypiuk J. Reversed-phase high-performance liquid chromatography on porous copolymers of different chemical structure. J Chrom A. 2000;898:13-21.

4. Small H, Stevens TS, Bauman WS. Novel ion exchange chromatographic method using conductimetric detection. Anal Chem. 1975;47:1801-9.

5. Saari-Nordhaus R, Anderson JM. Dual-column techniques for the simultaneous analysis of anions and cations. J Chromatogr A. 1992;602:127-33.

6. Yan D, Schwedt G. Simultaneous ion chromatography of inorganic anions together with some organic anions and alkaline earth metal cations using chelating agents as eluents. J Chromatogr A. 1990;516:383-93.

7. Grochowicz M, Gawdzik B. Permanently porous copolymeric microspheres based on aromatic methacrylates. React Funct Polym. 2011;71:625-33.

8. Grochowicz M, Gawdzik B. Preparation and characterization of porous crosslinked microspheres of new aromatic methacrylates. J Porous Mat. 2012. doi:10.1007/s10934-012-9603-0.

9. Podkościelna B. Photo- and thermally initiated polymerization of methacrylate monomer derivative of bis(4-hydroxyphenyl)sulfide with $N$-vinyl-2-pyrrolidone. J Thermal Anal Calorim. 2012; 107:703-8.

10. Samatya S, Kabay N, Tunel A. A hydrophilic matrix for boron isolation: monodisperse-porous poly(glycidyl methacrylate-coethylene dimethacrylate) particles carrying diol functionality. React Funct Polym. 2010;70:555-62.

11. Podkościelna B. Synthesis, modification, and porous properties of new glycidyl methacrylate copolymers. J Appl Polym Sci. 2011; 120:3020-6.

12. Pfaffa A, Barnerb L, Müllera AHE, Granville AM. Surface modification of polymericmicrospheres using glycopolymers for biorecognition. Europ Polym J. 2011;47:805-15.
13. Gazi M, Galli G, Bicak N. The rapid boron uptake by multihydroxyl functional hairy polymers. Sep Purif Technol. 2008; 62:484-8.

14. Zhou K, Tong L, Deng J, Yang W. Hollow polymeric microspheres grafted with optically active helical polymer chains: preparation and their chiral recognition ability. J Mater Chem. 2010;20:781-9.

15. Hill DJ, O'Donnell JH, Pomery PJ, Whittaker MR. A high resolution NMR investigation into the microstructure of HEMA and EEMA copolymers. Polym Gels Netw. 1995;3:85-97.

16. Creed JT, Magnuson ML, Pfaff JD, Brockhoff C. Determination of bromate in drinking waters by ion chromatography with inductively coupled plasma mass spectrometric detection. J Chromatogr A. 1996;753:261-7.

17. Kubań P, Dasgupta PK, Pohl C. Open tubular anion exchange chromatography. Controlled layered architecture of stationary phase by successive condensation polymerization. Anal Chem. 2007;79:5462-7.

18. Pohl C, Saini C. New developments in the preparation of anion exchange media based on hyperbranched condensation polymers. J Chromatogr A. 2008;1213:37-44.

19. Buszewski B, Jaćkowska M, Bocian S, Kosobucki P, Gawdzik B. Functionalized polymeric stationary phases for ion chromatography. J Sep Sci. 2011;34:601-8.

20. Smith MB, March J. Advanced organic chemistry: reactions, mechanisms, and structure. 5th ed. New York: Wiley-Interscience Publication; 2001.

21. Grochowicz M, Gawdzik B, Jaćkowska M, Buszewski B. Investigation of the thermal behavior of new silica-polymer anion exchangers. J Thermal Anal Calorim. 2012. doi:10.1007/s 10973-012-2635-5.

22. Grochowicz M, Bartnicki A, Gawdzik B. Synthesis of a new tetrafunctional monomer, 1,4-di(2-hydroxy-3-methacryloyloxypropoxy)

phenol, and its copolymerization. J Appl Polym Sci. 2008;107: 3718-26.

23. Jaćkowska M, Bocian S, Gawdzik B, Grochowicz M, Buszewski B. Influence of chemical modification on the porous structure of polymeric adsorbents. Mater Chem Phys. 2011;130:644-50.

24. Maciejewska M, Osypiuk-Tomasik J. Studies of sorption properties of porous copolymers of 1-vinyl-2-pyrrolidone. J Thermal Anal Calorim. 2013;111:1595-601.

25. Popescu LM, Piticescu RM, Stoiciu M, Vasile E, Trusca R. Investigation of thermal behaviour of hybrid nanostructures based on $\mathrm{Fe}_{2} \mathrm{O}_{3}$ and PAMAM dendrimers. $\mathrm{J}$ Therm Anal Calorim. 2012;110:357-62.

26. Khanam N, Mikoryak C, Draper RK, Balkus KJ Jr. Electrospun linear polyethyleneimine scaffolds for cell growth. Acta Biomater. 2007;3:1050-9.

27. Arndt EM, Gawryla MD, Schiraldi DA. Elastic, low density epoxy/clay aerogel composites. J Mater Chem. 2007;17:3525-9.

28. Marini A, Berbenni V, Capsoni D, Riccardi R, Zerlia T. Factors affecting the spectral response in a TG/FT-IR experiment. Appl Spectrosc. 1994;48:1468-71. 